\title{
Effects of oxygen limitation on sugar metabolism in yeasts: a continuous-culture study of the Kluyver effect
}

\author{
Ruud A. Weusthuis, Wiebe Visser, $†$ Jack T. Pronk, \\ $W$. Alexander Scheffers and Johannes P. van Dijken
}

Author for correspondence: Johannes P. van Dijken. Tel: +31 15 782387. Fax: + 3115782355.

Department of Microbiology and Enzymology, Kluyver Laboratory of Biotechnology, Delft University of Technology, Julianalaan 67, 2628 BC Delft, The Netherlands
Growth and metabolite formation were studied in oxygen-limited chemostat cultures of Saccharomyces cerevisiae CBS 8066 and Candida utilis CBS 621 growing on glucose or maltose at a dilution rate of $0.1 \mathrm{~h}^{-1}$. With either glucose or maltose $S$. cerevisiae could be grown under dual limitation of oxygen and sugar. Respiration and alcoholic fermentation occurred simultaneously and the catabolite fluxes through these processes were dependent on the magnitude of the oxygen feed. $C$. utilis could also be grown under dual limitation of glucose and oxygen. However, at very low oxygen feed rates (i.e. below $4 \mathrm{mmol} \mathrm{I}^{-1} \mathrm{~h}^{-1}$ ) growth was limited by oxygen only, as indicated by the high residual glucose concentration in the culture. In contrast to $S$. cerevisiae, $C$. utilis could not be grown anaerobically at a dilution rate of $0.1 \mathrm{~h}^{-1}$. With C. utilis absence of oxygen resulted in wash-out, despite the presence of ergosterol and Tween-80 in the growth medium. The behaviour of $C$. utilis with respect to maltose utilization in oxygen-limited cultures was remarkable: alcoholic fermentation did not occur and the amount of maltose metabolized was dependent on the oxygen supply. Oxygen-limited cultures of $C$. utilis growing on maltose always contained high residual sugar concentrations. These observations throw new light on the so-called Kluyver effect. Apparently, maltose is a non-fermentable sugar for C. utilis CBS 621, despite the fact that it can serve as a substrate for growth of this facultatively fermentative yeast. This is not due to the absence of key enzymes of alcoholic fermentation. Pyruvate decarboxylase and alcohol dehydrogenase were present at high levels in maltose-utilizing cells of $C$. utilis grown under oxygen limitation. It is concluded that the Kluyver effect, in C. utilis growing on maltose, results from a regulatory mechanism that prevents the sugar from being fermented. Oxygen is not a key factor in this phenomenon since under oxygen limitation alcoholic fermentation of maltose was not triggered.

Keywords: Saccharomyces cerevisiae, Candida utilis, sugar metabolism, oxygen limitation, Kluyver effect

\section{INTRODUCTION}

Oxygen is a key factor in the regulation of sugar metabolism in yeasts. In the presence of oxygen, virtually all yeasts can respire sugars to $\mathrm{CO}_{2}$ and water. The majority of the yeast species described so far are also
†Present address: Nutricia BV, Zoetermeer, The Netherlands. Abbreviations: $A D H$, alcohol dehydrogenase; $\mathrm{PDH}$, pyruvate dehydrogenase. capable of fermenting sugars to ethanol and carbon dioxide (Barnett et al., 1990; van Dijken et al., 1986). The capacity to ferment sugars to ethanol does not imply the ability to grow under anaerobic conditions. In fact, most facultatively fermentative yeasts do not grow well in the complete absence of oxygen, not even in complex media (Visser et al., 1990).

Oxygen-related physiological phenomena in yeasts have been categorized as four 'effects', the occurrence of which depends both on the yeast species and on the sugar 

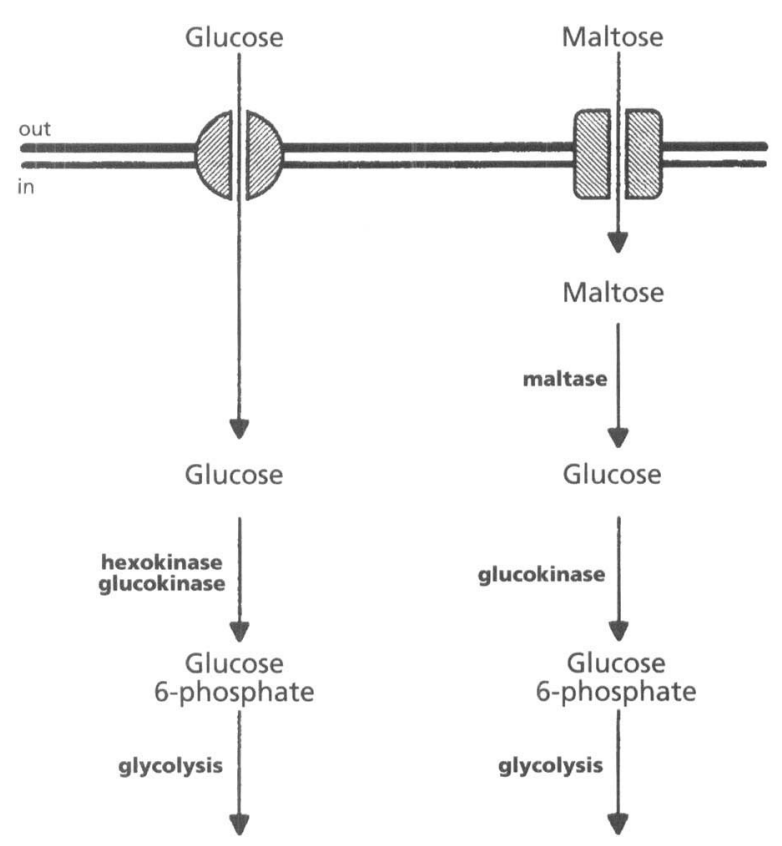

Fig. 1. Differences between glucose and maltose metabolism in yeasts. In this scheme it has been assumed that phosphorylation of glucose units derived from maltose occurs by glucokinase only, while glucose that is taken up from the medium can be phosphorylated by both glucokinase and hexokinase (Clifton et al., 1993).

substrate. The Pasteur effect has been defined as an inhibition of fermentative sugar metabolism by oxygen (Lagunas et al., 1982; Lagunas, 1986; Busturia \& Lagunas, 1986; Lloyd \& James, 1987). In contrast, the Custers effect describes the phenomenon that, in certain yeasts, fermentation is inhibited by the absence of oxygen (Custers, 1940; Scheffers, 1966; Carrascosa et al., 1981; Wijsman et al., 1984; Gaunt et al., 1988). The Crabtree effect, defined as the occurrence of fermentative metabolism in the presence of oxygen occurs in some yeasts when these are exposed to excess sugar (Fiechter et al., 1981 ; Petrik et al., 1983; Käppeli et al., 1985a, b; Käppeli, 1986; Käppeli \& Sonnleitner, 1986; Postma et al., 1988; 1989a, b; van Urk et al., 1988, 1989).

A fourth phenomenon, the Kluyver effect (Sims \& Barnett, 1978), is probably the least understood of these oxygen-related metabolic responses. It has been defined as follows: ' ... certain yeasts can utilize particular disaccharides aerobically but not anaerobically, although these yeasts can use one or more of the component hexoses anaerobically' (Sims \& Barnett, 1978). A screening for the occurrence of the Kluyver effect among yeast species revealed that it is widespread among facultatively fermentative yeasts, the pattern of disaccharide fermentation being strongly strain-dependent (Sims \& Barnett, 1978).

Clearly, the Kluyver effect must be caused by differences between monosaccharide and disaccharide metabolism. As shown in Fig. 1, this leaves three possibilities: sugar transport, disaccharide hydrolysis or sugar-specific regulatory mechanisms.
A number of hypotheses have been proposed regarding the cause of the Kluyver effect. Kluyver \& Custers (1940) postulated that the phenomenon might be caused by a reversible inactivation of the disaccharide hydrolase under anaerobic conditions. Later on, several authors proposed an effect of oxygen on disaccharide transport, either direct (e.g. by an effect on the conformation of the sugar carrier) or indirect [e.g. by an inadequate energy supply for active uptake of disaccharides during anaerobic fermentation (Barnett \& Sims, 1982; Sims et al., 1984; Schulz \& Höfer, 1986; Höfer \& Nassar, 1987)]. Alternatively, regulation of the key fermentative enzyme pyruvate decarboxylase by the sugar substrate has been suggested (Sims \& Barnett, 1991). Furthermore, in recent papers it has been presumed that combinations of the factors shown in Fig. 1 may cause the Kluyver effect (Sims et al., 1991; Barnett, 1992).

The data presented in the original screening of yeast species by Sims \& Barnett (1978) originated from two types of taxonomic tests. 'Aerobic' growth tests were performed in slowly shaking test-tubes; 'anaerobic' growth and fermentation tests were performed in static incubation of Durham tubes containing an inverted vial for monitoring gas production. It is clear that in the screening by Sims \& Barnett (1978) the 'aerobic' cultures are likely to have been oxygen-limited. On the other hand, some oxygen must also have entered the static 'anaerobic' cultures.

Since none of the facultatively fermentative yeasts that exhibit the Kluyver effect are capable of anaerobic growth (Visser et al., 1990), occurrence of the Kluyver effect must be confined to oxygen-limited growth conditions. Although oxygen has often been implicated as a key factor in its occurrence, the Kluyver effect has not yet been studied under controlled oxygen feed regimes.

The aim of the present work was to investigate the function of oxygen in the Kluyver effect. For this purpose, the effect of the oxygen feed rate on sugar metabolism was studied in sugar-limited chemostat cultures. C. utilis was chosen as a model organism that exhibits the Kluyver effect for maltose (Sims \& Barnett, 1978), whereas S. cerevisiae CBS 8066 is Kluyver-negative for this disaccharide (Weusthuis et al., 1993). Since both strains are capable of respiratory and fermentative glucose metabolism, cultures grown on glucose were included as references. The experimental results were compared to those predicted by a simple metabolic model.

\section{METHODS}

Organisms and maintenance. Saccharomyces cerevisiae CBS 8066 and Candida utilis CBS 621 were obtained from the Centraalbureau voor Schimmelcultures (Delft, The Netherlands) and maintained on malt agar slants at $4{ }^{\circ} \mathrm{C}$.

Chemostat cultivation. Chemostat cultivation was performed in 2 litre fermenters (Applikon) at a dilution rate of $0 \cdot 10 \mathrm{~h}^{-1}$, a temperature of $30^{\circ} \mathrm{C}$ and a stirrer speed of 750 r.p.m. The culture $\mathrm{pH}$ was maintained at 5.0 by automatic addition of $2 \mathrm{M} \mathrm{KOH}$, via an Applikon ADI-1030 biocontroller. The working volume of the culture was kept at $1 \cdot 1$ litre by removal of effluent from the middle of the culture, via an Applikon 
electrical level controller. This set-up ensured that biomass concentrations in the effluent line different by less than $1 \%$ from those in samples taken directly from the culture. To achieve an identical fermenter geometry, positions of baffles, pipes, impellers and sensors were kept the same in all experiments. To avoid loss of volatile metabolites, the condenser was cooled to $2{ }^{\circ} \mathrm{C}$, using a cryostat. The mineral medium, supplemented with vitamins, trace elements and the anaerobic growth factors ergosterol (5,7,22-ergostatrien-3 $\beta$-ol; Sigma E-6510) and Tween-80 (polyoxyethylene-sorbitanmonooleate; Merck 822187) (see Andreasen \& Stier, 1953, 1954) was prepared as described by Weusthuis et al. (1993). Glucose or maltose monohydrate, the growth factors and vitamins were added to the media after separate sterilization (Weusthuis et al., 1993). Both the oxygen transfer properties of the cultures and the optimum Tween-80 concentration (Verduyn et al., 1990) are functions of the biomass concentration in the reactor. Therefore, it was attempted to keep the biomass concentration in the cultures constant by increasing the reservoir concentration of the sugars with decreasing oxygen feed. In practice, biomass concentrations in the cultures typically varied between 2 and $3 \mathrm{~g}$ dry weight $\mathrm{l}^{-1}$, with sugar concentrations in the reservoir medium ranging from 5 to $50 \mathrm{~g} \mathrm{l}^{-1}$. The purity of the chemostat cultures was routinely checked by phase contrast microscopy at $1000 \times$ magnification.

Oxygenation of the chemostat cultures. Oxygen was added to the cultures as air, using a peristaltic pump. The air flow rates ranged from 0 to $100 \mathrm{ml} \mathrm{min}^{-1}$. The temperature of the ingoing air was kept constant at $20^{\circ} \mathrm{C}$. The overall gas flow into the cultures was maintained at $0.51 \mathrm{~min}^{-1}$ by the supplementary addition of nitrogen gas, using a Brooks 5876 mass flow controller. Addition of nitrogen gas assured good mixing of the air with the culture fluid and promoted anaerobiosis when air was not added. To minimize diffusion of atmospheric oxygen into the cultures, the entire fermentation set-up (including medium reservoir and effluent vessel) was equipped with Norprene tubing and the reservoir vessel was flushed with nitrogen gas. The dissolved-oxygen concentration in the cultures was monitored with an Ingold polarographic oxygen electrode.

Gas analysis. Gas flows were measured with a self-constructed device, consisting of an inverted glass cylinder, filled with water. The cylinder was placed in a water-filled reservoir to prevent outflow of water, without touching the reservoir walls. A gas flow directed into the cylinder causes water to flow into the reservoir, which rested on an electronic balance. The weight of the water displaced per unit of time could, after the necessary corrections (e.g. ambient air pressure, temperature, pressure falls), be used to calculate the gas flow. Using this device, measurements were reproducible within $0.5 \%$. Since the gas flows (nitrogen and air) into the cultures had to be interrupted before measurement, they were measured both before and immediately after steady-state analysis. Due to a slight loss of resilience of new tubing, usually a small difference between these measurements was found (on average $2 \%$ ). The steady-state value was used in the calculations. The exhaust gas flow was determined on-line during the steady states. The oxygen content of the exhaust gas was determined with a Servomex oxygen analyser, $\mathrm{CO}_{2}$ content with a Beckman infra-red $\mathrm{CO}_{2}$ analyser. The exhaust gas entering both analysers was dried with a Perma Pure Dryer. Specific rates of $\mathrm{CO}_{2}$ production and $\mathrm{O}_{2}$ consumption were calculated according to van Urk et al. (1988). The amount of $\mathrm{CO}_{2}$ leaving the culture with the effluent was negligible.

Metabolite analysis. Glucose and maltose concentrations were determined as described by Weusthuis et al. (1993). Ethanol, glycerol and organic acids as pyruvate, succinate, fumarate and 2-oxoglutarate were determined by HPLC (Weusthuis et al., 1993). Ethanol concentrations were also determined with an enzymic assay (based on alcohol oxidase; EK 001 Leeds Biochemicals). Both methods gave identical results.

Culture dry weights. Dry weights of culture samples were determined using a microwave oven and $0.45 \mu \mathrm{m}$ membrane filters as described by Postma et al. (1989b). Parallel samples varied by less than $1 \%$.

Enzyme assays. Preparation of cell-free extracts and assays of pyruvate decarboxylase (EC 4.1.1.1) and alcohol dehydrogenase (EC 1.1.1.1) activity were performed as described by Postma et al. (1989b).

Presentation of data. Several experimental approaches can be used to study the effects of oxygen on yeast metabolism. One possibility is to study the effect of dissolved-oxygen concentration (Brown \& Rose, 1969; Moss et al., 1969; Cysewski \& Wilke, 1976; Nishizawa et al., 1980; Furukawa et al., 1983; Laplace et al., 1991). However, at limiting oxygen supply rates, the dissolved-oxygen concentration falls below $1 \%$ air saturation and becomes difficult to measure accurately. Moreover, the anaerobic growth factors Tween-80 and ergosterol tend to foul oxygen electrode membranes, thereby further reducing the reliability of the measurements.

An alternative approach is to study the effect of oxygen feed rate (Oura, 1977; Grosz \& Stephanopoulos, 1990; Kuriyama \& Kobayashi, 1993). The effect of oxygen feed rate on growth and metabolism is strongly influenced by the gas transfer characteristics of the cultures, which are affected by biomass density and fermenter geometry. However, when oxygen feed rates are varied in identical fermentation set-ups with approximately equal biomass concentrations, this should allow a comparative study involving different carbons sources and yeast species. Nevertheless, data from this type of comparative studies cannot easily be extrapolated to alternative experimental set-ups.

In well-mixed systems, effects of gas transfer characteristics can be eliminated by using the specific oxygen uptake rate $\left(q_{\mathrm{o}_{2}}\right)$ as the experimental variable. This should allow extrapolation to other well-mixed fermenter set-ups, even if these exhibit different gas transfer properties. Unfortunately, since $q_{\mathrm{O}_{2}}$ is a derived parameter, its use will inevitably result in more scatter of the experimental data. In the present study, we have tried to relate experimental data to specific oxygen uptake rates whenever possible. However, at very low oxygen feeds, the off-gas oxygen analysis was not sufficiently sensitive to accurately calculate $q_{\mathrm{O}_{2}}$ (in some cases, this even resulted in negative apparent oxygen uptake rates). To enable comparison, even at low oxygen feed rates, of the four sets of experiments (two yeast species and two substrates), we attempted to keep fermenter geometry and biomass concentrations in all experiments constant (see above).

\section{RESULTS}

\section{Relation between oxygen consumption rate and metabolic fluxes in S. cerevisiae: a simplified model}

When the oxygen feed to sugar-limited cultures of the facultatively anaerobic yeast $S$. cerevisiae is varied, the biomass yield on sugar can be expected to vary between the growth yield observed under anaerobic conditions and the aerobic, 'respiratory' biomass yield. Because of the higher energetic efficiency of respiratory sugar metabolism, the biomass yield during respiratory growth 
Table 1. Effect of oxygen feed rate on oxygen and substrate utilization and production of biomass and ethanol by S. cerevisiae CBS 8066 grown in chemostat cultures $\left(D=0.10 \mathrm{~h}^{-1}\right)$ with glucose as a carbon source

Oxygen $_{\text {In }}$, oxygen feed rate. Oxygen ${ }_{\text {Out }}$, amount of oxygen leaving the culture. Glucose ${ }_{I n}$, reservoir concentration of sugar. Glucose $_{\text {Out }}$, residual sugar concentration in culture.

\begin{tabular}{|c|c|c|c|c|c|}
\hline \multicolumn{2}{|c|}{$\begin{array}{c}\text { Oxygen } \\
\left(\mathrm{mmol} \mathrm{l}^{-1} \mathrm{~h}^{-1}\right)\end{array}$} & \multicolumn{2}{|c|}{$\begin{array}{c}\text { Glucose } \\
\left(\mathrm{g} \mathrm{l}^{-1}\right)\end{array}$} & \multirow{2}{*}{$\begin{array}{c}\text { Dry } \\
\text { weight } \\
\left(\mathrm{g} \mathrm{l}^{-1}\right)\end{array}$} & \multirow[t]{2}{*}{$\begin{array}{c}\text { Ethanol } \\
\text { (mM) }\end{array}$} \\
\hline In & Out & In & Out & & \\
\hline 0 & 0.32 & $24 \cdot 6$ & $<0.1$ & $2 \cdot 52$ & 242 \\
\hline 0.70 & 0.85 & $22 \cdot 8$ & $<0 \cdot 1$ & $2 \cdot 64$ & 201 \\
\hline 0.93 & 0.73 & $23 \cdot 7$ & $<0 \cdot 1$ & $2 \cdot 70$ & 240 \\
\hline $4 \cdot 7$ & $2 \cdot 6$ & $15 \cdot 5$ & $<0 \cdot 1$ & $2 \cdot 56$ & 172 \\
\hline $7 \cdot 3$ & $6 \cdot 0$ & $11 \cdot 4$ & $<0.1$ & 1.99 & 99 \\
\hline 13.5 & 8.9 & $7 \cdot 6$ & $<0.1$ & $2 \cdot 07$ & 58 \\
\hline $17 \cdot 5$ & $13 \cdot 7$ & 6.5 & $<0.1$ & $2 \cdot 15$ & 41 \\
\hline $24 \cdot 2$ & $18 \cdot 2$ & $5 \cdot 1$ & $<0.1$ & $2 \cdot 67$ & 14 \\
\hline $33 \cdot 1$ & $25 \cdot 6$ & $5 \cdot 2$ & $<0.1$ & $3 \cdot 18$ & $<1$ \\
\hline $46 \cdot 6$ & $39 \cdot 3$ & $4 \cdot 6$ & $<0.1$ & $2 \cdot 79$ & $<1$ \\
\hline
\end{tabular}

Table 2. Effect of oxygen feed rate on oxygen and substrate utilization and production of biomass and ethanol by S. cerevisiae CBS 8066 grown in chemostat cultures $\left(D=0.10 \mathrm{~h}^{-1}\right)$ with maltose as a carbon source

\begin{tabular}{|c|c|c|c|c|c|}
\hline \multicolumn{2}{|c|}{$\begin{array}{c}\text { Oxygen } \\
\left(\mathrm{mmol}^{-1} \mathrm{~h}^{-1}\right)\end{array}$} & \multicolumn{2}{|c|}{$\begin{array}{c}\text { Maltose } \\
\left(\mathrm{g} \mathrm{t}^{-1}\right)\end{array}$} & \multirow{2}{*}{$\begin{array}{c}\text { Dry } \\
\text { weight } \\
\left(\mathrm{g} \mathrm{l}^{-1}\right)\end{array}$} & \multirow[t]{2}{*}{$\begin{array}{c}\text { Ethanol } \\
(\mathrm{mM})\end{array}$} \\
\hline In & Out & In & Out & & \\
\hline 0 & 0 & $30 \cdot 0$ & $<0.1$ & $2 \cdot 16$ & 259 \\
\hline 0 & 0 & $30 \cdot 3$ & $0 \cdot 1$ & $2 \cdot 13$ & 259 \\
\hline $5 \cdot 4$ & $4 \cdot 2$ & $24 \cdot 0$ & $0 \cdot 2$ & $2 \cdot 40$ & 211 \\
\hline $10 \cdot 8$ & $8 \cdot 3$ & $20 \cdot 5$ & $<0.1$ & $2 \cdot 55$ & 121 \\
\hline $18 \cdot 7$ & $15 \cdot 4$ & $14 \cdot 1$ & $<0 \cdot 1$ & $2 \cdot 36$ & 80 \\
\hline $22 \cdot 3$ & $17 \cdot 3$ & $9 \cdot 9$ & $<0 \cdot 1$ & $2 \cdot 51$ & 41 \\
\hline $24 \cdot 8$ & $19 \cdot 1$ & $7 \cdot 7$ & $<0 \cdot 1$ & 2.68 & 26 \\
\hline $30 \cdot 8$ & $24 \cdot 8$ & $5 \cdot 3$ & $<0 \cdot 1$ & $2 \cdot 41$ & 35 \\
\hline $35 \cdot 3$ & $29 \cdot 6$ & $4 \cdot 1$ & $<0.1$ & $2 \cdot 52$ & $<1$ \\
\hline $40 \cdot 2$ & $34 \cdot 0$ & $4 \cdot 1$ & $<0 \cdot 1$ & $2 \cdot 51$ & $<1$ \\
\hline $45 \cdot 8$ & $39 \cdot 8$ & $4 \cdot 6$ & $<0 \cdot 1$ & $2 \cdot 71$ & $<1$ \\
\hline
\end{tabular}

is ca. 5-fold higher than that under strictly anaerobic conditions (Verduyn et al., 1990, 1991). Over this range of oxygen feeds, the specific oxygen uptake rate can be expected to vary between zero (under anaerobic conditions) and the rate corresponding to sugar-limited, fully respiratory growth.

At submaximal oxygen consumption rates, both respiration and fermentation can contribute to glucose metabolism. An increase of the oxygen consumption rate implies that more sugar is respired, thereby increasing the biomass yield. Alternatively, an increase of the biomass yield can be achieved by increasing the concentration of sugar in the feed rate, which allows more sugar to be fermented. Growth under these conditions can therefore be described as dually limited by oxygen and glucose.

A simplified model describing biomass yield and metabolic fluxes in S. cerevisiae cultures growing under this dual limitation can be constructed by assuming that the energetic efficiency of fermentative and respiratory sugar metabolism is not affected by the simultaneous occurrence of both processes. If this assumption holds, and products other than $\mathrm{CO}_{2}$, ethanol, biomass and water are neglected, the biomass yield in the oxygen- and sugar-limited cultures will be a simple function of the fraction of glucose that is metabolized by respiration. This fraction is equal to the ratio of the actual specific oxygen uptake rate $\left(q_{\mathrm{O}_{2}}\right)$ and the specific oxygen uptake rate during fully respiratory growth $\left(q_{\mathrm{O}_{2}, \mathrm{R}}\right)$. The actual biomass yield on glucose is given by equation 1 , in which $Y$ is the actual biomass yield, $Y_{\mathrm{F}}$ is the anaerobic, fermentative biomass yield and $Y_{\mathrm{R}}$ is the aerobic, respiratory biomass yield on sugar.

$\frac{1}{Y}=\frac{1}{Y_{\mathrm{F}}}\left(1-\frac{q_{\mathrm{O}_{2}}}{q_{\mathrm{O}_{2}, \mathrm{R}}}\right)+\frac{1}{Y_{\mathrm{R}}} \frac{q_{\mathrm{o}_{2}}}{q_{\mathrm{o}_{2}, \mathrm{R}}}$

Equation 1 is based on the assumption that the fraction of sugar that is fermented $\left(1 / Y_{\mathrm{F}}\right)$ decreases linearly with increasing $q_{\mathrm{O}_{2}}$. Correspondingly, with increasing $q_{\mathrm{O}_{2}}$, the specific ethanol production rate $\left(q_{\text {ethanol }}\right)$ will decrease linearly from the rate that is observed during anaerobic growth $\left(q_{\text {ethanol,F }}\right)$ to zero, according to equation 2 .

$q_{\mathrm{ethanol}}=q_{\mathrm{ethanol, \textrm {F }}}\left(1-\frac{q_{\mathrm{O}_{2}}}{q_{\mathrm{O}_{2}, \mathrm{R}}}\right)$

Dissimilatory production of $\mathrm{CO}_{2}$ occurs both during respiration and fermentation. During complete respiratory dissimilation of glucose, the rate of $\mathrm{CO}_{2}$ production is equal to the oxygen consumption rate [the respiratory quotient (RQ) being 1]. The rate of fermentative $\mathrm{CO}_{2}$ production during alcoholic fermentation should be equal to the specific ethanol production rate given by equation 2.

Because yeast biomass is more oxidized than the substrate sugars, production of $\mathrm{CO}_{2}$ also occurs as a result of assimilatory processes (see e.g. Bruinenberg et al., 1984; Gommers et al., 1988). If it is assumed that the biomass composition does not vary substantially, the specific rate of assimilatory $\mathrm{CO}_{2}$ production should not be influenced by the oxygen feed rate. For $S$. cerevisiae cultures growing at a dilution rate of $0.10 \mathrm{~h}^{-1}$, an assimilatory $q_{\mathrm{CO}_{2}, \mathrm{~A}}$ of $0.58 \mathrm{mmol} \mathrm{g}^{-1} \mathrm{~h}^{-1}$ has been reported by Verduyn et al. (1990). When the three sources of $\mathrm{CO}_{2}$ production are combined, this results in equation 3 .

$q_{\mathrm{CO}_{2}}=q_{\mathrm{CO}_{2}, \mathrm{~A}}+q_{\mathrm{O}_{2}}+q_{\text {ethanol }}$

Substitution of equation 2 in equation 3 gives equation 4 , which indicates also that the specific $\mathrm{CO}_{2}$ production rate of the cultures is a linear function of $q_{\mathrm{O}_{2}}$.

$q_{\mathrm{CO}_{2}}=q_{\mathrm{CO}_{2}, \mathrm{~A}}+q_{\mathrm{O}_{2}}+q_{\text {ethanol, } \mathrm{F}}\left(1-\frac{q_{\mathrm{O}_{2}}}{q_{\mathrm{O}_{2}, \mathrm{R}}}\right)$ 


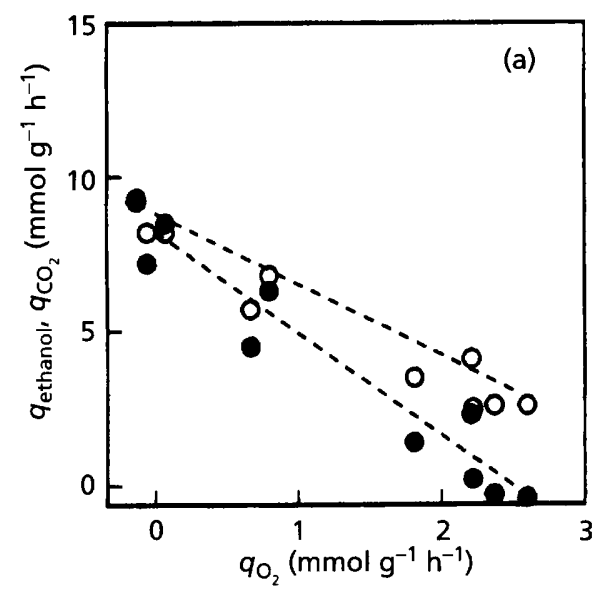

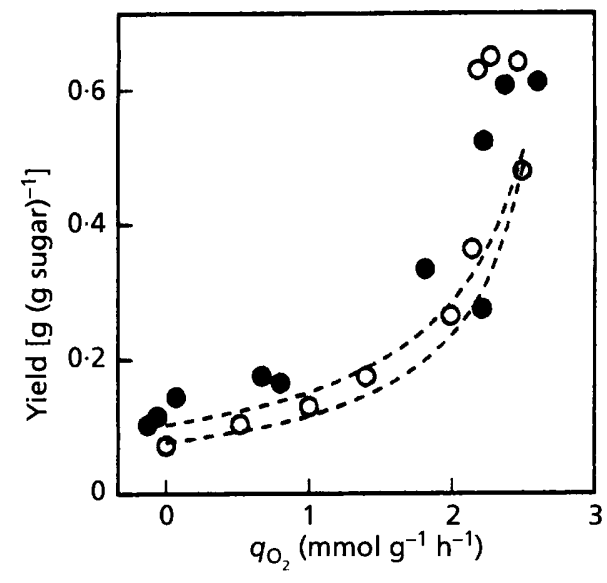

Fig. 2

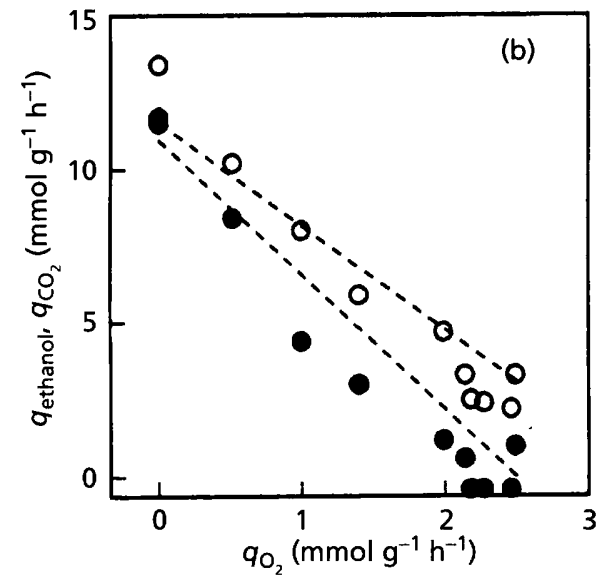

Fig. 3

Fig. 2. Relation between the specific oxygen uptake rate $\left(q_{O_{2}}\right)$ and biomass yield of $S$. cerevisiae CBS 8066, grown at different oxygen feed rates in chemostat cultures $\left(D=0.10 \mathrm{~h}^{-1}\right)^{2}$, with glucose $(\Theta)$ or maltose $(O)$ as a carbon and energy source. The data were fitted with equation 1 (dashed lines). Note that in this and the following figures, some negative $q_{\mathrm{O}_{2}}$ values are presented. This is due to the inaccuracy of the gas analysis at very low oxygen feed rates (see Methods).

Fig. 3. Relation between the specific oxygen uptake rate $\left(q_{O_{2}}\right)$ and the specific production rates of ethanol ( $\left.q_{\text {ethanol }}, \theta\right)$ and $\mathrm{CO}_{2}\left(q_{\mathrm{CO}_{2}}, O\right)$ of $S$. cerevisiae CBS 8066, grown at different oxygen feed rates in chemostat cultures $\left(D=0.10 \mathrm{~h}^{-1}\right)$, with glucose (a) or maltose (b) as a carbon and energy source. The ethanol data were fitted with equation 2 , the $\mathrm{CO}_{2}$ data with equation 4 (dashed lines).

\section{Effect of oxygen feed on growth of $S$. cerevisiae on glucose and maltose}

The effects of oxygen on the physiology of $S$. cerevisiae were studied by varying the oxygen feed rate to glucoseand maltose-limited chemostat cultures grown at a dilution rate of $0 \cdot 10 \mathrm{~h}^{-1}$. At oxygen feed rates above $30 \mathrm{mmol} \mathrm{l}^{-1} \mathrm{~h}^{-1}$ and sugar concentrations below $5.0 \mathrm{~g} \mathrm{l}^{-1}$, growth of $S$. cerevisiae was not oxygen-limited: a further increase in air supply did not result in higher biomass yields (Tables 1 and 2). Growth was fully respiratory, as was evident from the absence of ethanol in the culture supernatants (Tables 1 and 2) and an RQ of approximately 1 (Fig. 3). The $q_{\mathrm{O}_{2}}$ of these oxygen-sufficient, glucoselimited chemostat cultures was ca. $2.5 \mathrm{mmol} \mathrm{g}^{-1} \mathrm{~h}^{-1}$ (Fig. 2). When $q_{\mathrm{O}_{2}}$ was lowered by decreasing the oxygen feed rate, alcoholic fermentation set in (Tables 1 and 2 ; Fig. 3). This coincided with a decrease of the biomass yield (Fig. 2).

Over a range of oxygen consumption rates, respiratory and fermentative glucose metabolism occurred simultaneously. In these cultures, the biomass concentration could be increased either by increasing the oxygen feed rate (Fig. 2), or by increasing the sugar concentration in the reservoir medium (which led to increased alcoholic fermentation; data not shown). Therefore, such cultures grew under a dual limitation of sugar and oxygen.

Qualitatively, equation 1 gave a good description of the observed biomass yields at non-saturating oxygen feeds (Fig. 2). However, the apparent biomass yield of $0.63 \pm$ $0.02 \mathrm{~g}$ (g sugar) ${ }^{-1}$ (Fig. 2) in the oxygen-sufficient cultures 
Table 3. Effect of oxygen feed rate on oxygen and substrate utilization and production of biomass, ethanol and pyruvate by $C$. utilis CBS 621 grown in chemostat cultures $\left(D=0.10 \mathrm{~h}^{-1}\right)$ with glucose as a carbon source

\begin{tabular}{|c|c|c|c|c|c|c|}
\hline \multicolumn{2}{|c|}{$\begin{array}{c}\text { Oxygen } \\
\left(\mathrm{mmol} \mathrm{h}^{-1} 1^{-1}\right)\end{array}$} & \multicolumn{2}{|c|}{$\begin{array}{c}\text { Glucose } \\
\left(\mathrm{g} \mathrm{l}^{-1}\right)\end{array}$} & \multirow{2}{*}{$\begin{array}{c}\text { Dry } \\
\text { weight } \\
\left(\mathrm{g} \mathrm{l}^{-1}\right)\end{array}$} & \multirow{2}{*}{$\begin{array}{c}\text { Ethanol } \\
(\mathrm{mM})\end{array}$} & \multirow[t]{2}{*}{$\begin{array}{c}\text { Pyruvate } \\
\text { (mM) }\end{array}$} \\
\hline In & Out & In & Out & & & \\
\hline 0.17 & $0 \cdot 51$ & $45 \cdot 5$ & $28 \cdot 3$ & $1 \cdot 50$ & 170 & $5 \cdot 8$ \\
\hline 0.33 & $0 \cdot 61$ & $45 \cdot 5$ & $17 \cdot 3$ & 1.99 & 265 & $4 \cdot 1$ \\
\hline 0.77 & 0.69 & $45 \cdot 5$ & $17 \cdot 8$ & $2 \cdot 00$ & 262 & $3 \cdot 8$ \\
\hline $1 \cdot 8$ & $1 \cdot 3$ & $45 \cdot 5$ & 0.9 & $2 \cdot 22$ & 340 & $8 \cdot 7$ \\
\hline $2 \cdot 9$ & $2 \cdot 3$ & $45 \cdot 5$ & $16 \cdot 2$ & $2 \cdot 50$ & 242 & $8 \cdot 0$ \\
\hline $4 \cdot 3$ & $3 \cdot 0$ & $28 \cdot 4$ & $<0.1$ & $3 \cdot 20$ & 252 & $2 \cdot 4$ \\
\hline $9 \cdot 3$ & $5 \cdot 8$ & $14 \cdot 2$ & $<0.1$ & $2 \cdot 70$ & 90 & $0 \cdot 2$ \\
\hline $11 \cdot 4$ & $8 \cdot 9$ & $10 \cdot 5$ & $<0.1$ & $2 \cdot 21$ & 82 & $<0 \cdot 1$ \\
\hline 16.7 & $13 \cdot 1$ & $7 \cdot 7$ & $<0.1$ & $2 \cdot 38$ & 42 & $<0 \cdot 1$ \\
\hline $18 \cdot 6$ & $14 \cdot 9$ & $7 \cdot 7$ & $<0.1$ & 2.57 & 54 & $<0 \cdot 1$ \\
\hline $24 \cdot 4$ & $18 \cdot 8$ & 6.4 & $<0.1$ & $2 \cdot 99$ & 24 & $<0.1$ \\
\hline $22 \cdot 3$ & $15 \cdot 9$ & 5.9 & $<0.1$ & $3 \cdot 14$ & 17 & $<0 \cdot 1$ \\
\hline $32 \cdot 6$ & $25 \cdot 3$ & $4 \cdot 6$ & $<0.1$ & 3.03 & $<1$ & $<0 \cdot 1$ \\
\hline $47 \cdot 8$ & $40 \cdot 1$ & $4 \cdot 6$ & $<0 \cdot 1$ & $2 \cdot 96$ & $<1$ & $<0 \cdot 1$ \\
\hline
\end{tabular}

was substantially higher than the $0.51 \mathrm{~g} \mathrm{~g}^{-1}$ reported by Verduyn et al. (1991) for aerobic growth of $S$. cerevisiae. An explanation for the high biomass yield is that all cultures were supplied with the anaerobic growth factors Tween80 and ergosterol. Both were added as a stock solution in ethanol, resulting in an ethanol concentration of ca. $12 \mathrm{mM}$ in the reservoir media. Under oxygen-sufficient growth conditions, ethanol was co-metabolized by the cultures, as evident from the apparent 'negative' $q_{\text {ethanol }}$ at high oxygen feed rates (Fig. 3). Also oleic acid, added as Tween-80, may have a slight carbon-sparing effect and thus contribute to the biomass yield. When a correction is made for co-metabolism of ethanol (by assuming a growth yield of $0.61 \mathrm{~g} \mathrm{~g}^{-1}$ on ethanol; Verduyn et al., 1991), the corrected growth yield on glucose under oxygen-sufficient conditions would be $0.53 \mathrm{~g} \mathrm{~g}^{-1}$.

Both with glucose and maltose, $q_{\text {ethanol }}$ and $q_{\mathrm{CO}_{2}}$ increased with decreasing $q_{\mathrm{O}_{2}}$, to reach a maximum in the anaerobic cultures (Fig. 3). Equations 2 and 4 gave a good fit of the experimental data.

The main difference between growth of $S$. cerevisiae on glucose and maltose was the consistently lower biomass yield (Fig. 2) and higher $q_{\text {ethanol }}$ (Fig. 3) during oxygenlimited growth on maltose. The lower growth efficiency with maltose as the energy source can be fully explained by the fact that, unlike glucose, maltose is transported via a proton symport mechanism in S. cerevisiae. The net energy requirement for maltose transport is $1 \mathrm{~mol}$ ATP per mol maltose. Therefore, when maltose metabolism is fully fermentative, 1 out of the 4 ATP produced in glycolysis is used for maltose uptake, leading to a $25 \%$ lower biomass yield and a $43 \%$ higher $q_{\text {ethanol }}$ (Weusthuis et al., 1993). This tendency was indeed observed during anaerobic growth on maltose and glucose (Figs 2 and 3 ).
When sugar metabolism is respiratory, the ATP yield on maltose is much higher, and it is no longer possible to detect significant differences between the biomass yields on glucose and maltose (Fig. 2).

\section{Effects of oxygen feed on growth of Candida utilis on glucose}

As in S. cerevisiae, glucose metabolism of C. utilis was fully respiratory at oxygen feed rates above $30 \mathrm{mmol} \mathrm{l}^{-1} \mathrm{~h}^{-1}$ (Table 3). When the oxygen feed rate was reduced below this value, corresponding to an oxygen consumption rate of $2.5 \mathrm{mmol} \mathrm{g}^{-1} \mathrm{~h}^{-1}$, the biomass yield decreased (Fig. 4) and alcoholic fermentation set in (Table 3, Fig. 5).

At oxygen feed rates between 4.3 and $30 \mathrm{mmol} \mathrm{l}^{-1} \mathrm{~h}^{-1}$, virtually all the glucose was consumed (Table 3 ), with respiration and fermentation occurring simultaneously (Fig. 5). Qualitatively, the behaviour of the $C$. utilis cultures over this range of oxygen feeds was very similar to that of $S$. cerevisiae and growth could be considered as dually limited by glucose and oxygen (Table 3, Figs 4 and 5). However, when the oxygen feed rate was decreased below $4.3 \mathrm{mmol} \mathrm{l}^{-1} \mathrm{~h}^{-1}$, the residual glucose concentration in the cultures increased from below $0 \cdot 1 \mathrm{~g} \mathrm{l}^{-1}$ to $28.3 \mathrm{~g}^{-1}$, resulting in a decrease of the culture dry weights (Table 3). At these low oxygen feed rates, the biomass concentration in the cultures could no longer be increased by adding more glucose to the reservoir media. Apparently, at these low oxygen feed rates, growth of C. utilis was only limited by oxygen.

Attempts to grow $C$. utilis on glucose at oxygen consumption rates below $0 \cdot 17 \mathrm{mmol} \mathrm{g}^{-1} \mathrm{~h}^{-1}$ resulted in washout. Apparently, the maximum anaerobic growth rate of C. utilis is lower than the dilution rate $\left(0 \cdot 10 \mathrm{~h}^{-1}\right)$. This is in agreement with the reported maximum growth rate of C. utilis in anaerobic batch cultures $\left(0.01 \mathrm{~h}^{-1}\right.$; Visser et al., 1990).

As mentioned above for $S$. cerevisiae, the biomass yield of C. utilis under fully aerobic, respiratory conditions was higher than the value of $0.51 \mathrm{~g} \mathrm{~g}^{-1}$ reported by Verduyn et al. (1991), probably due to the presence of ethanol and oleic acid in the media. In view of the inability of $C$. utilis to grow anaerobically, the experimental data could not be fitted with equations 1 to 4 . However, it is clear from Fig. 5 that during dual-substrate-limited growth, $q_{\text {ethanol }}$ and $q_{\mathrm{CO}_{2}}$ did not increase linearly with decreasing $q_{\mathrm{O}_{2}}$ as predicted by equations 2 and 4 . The observed nonlinearity suggests that either fermentative metabolism or respiratory metabolism changes under dual substrate limitation. Factors that may be involved are changes in biomass composition or composition of the respiratory chain.

Compared to S. cerevisiae, the maximum $q_{\text {ethanol }}$ of C. utilis at very low oxygen feeds was substantially higher and the biomass yield correspondingly lower (Figs 4 and 5). This lower efficiency of fermentative growth may be due to the involvement of a proton symport carrier in glucose transport by $C$. utilis. Also increased maintenance requirements, for example caused by the production of uncoupling weak acids, may contribute to the high $q_{\text {ethanol }}$ at 


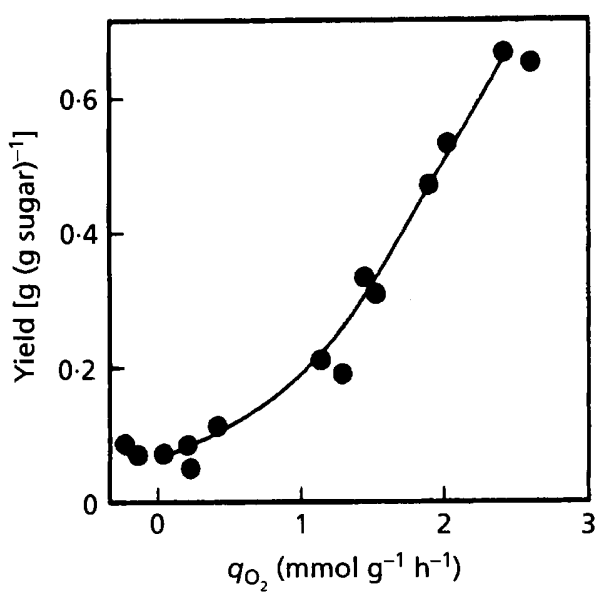

Fig. 4

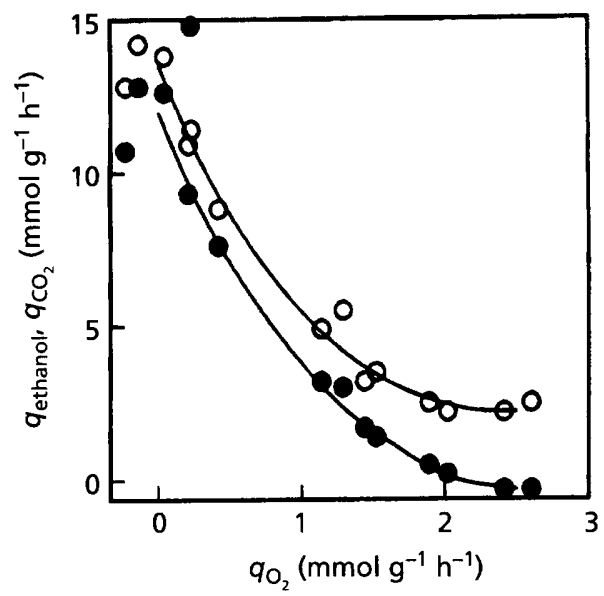

Fig. 5

Fig. 4. Relation between the specific oxygen uptake rate $\left(q_{\mathrm{O}_{2}}\right)$ and the biomass yield of $C$. utilis CBS 612 , grown at different oxygen feed rates in chemostat cultures $\left(D=0.10 \mathrm{~h}^{-1}\right)$, with glucose as a carbon and energy source.

Fig. 5. Relation between the specific oxygen uptake rate $\left(q_{\mathrm{o}_{2}}\right)$ and the specific production rates of ethanol $\left(q_{\text {ethanol, }}, \mathbf{Q}\right)$ and $\mathrm{CO}_{2}\left(q_{\mathrm{CO}_{2},} O\right)$ of $C$. utilis CBS 612 , grown at different oxygen feed rates in chemostat cultures $\left(D=0.10 \mathrm{~h}^{-1}\right)$, with glucose as a carbon and energy source.

low oxygen feeds. Indeed, organic acid concentrations increased with decreasing oxygen feed (data not shown), with pyruvate concentrations up to $8 \mathrm{mM}$ occurring in oxygen-limited $C$. utilis cultures (Table 3 ).

Table 4. Effect of oxygen feed rate on oxygen and substrate utilization and production of biomass, ethanol and pyruvate by $C$. utilis CBS 621 grown in chemostat $\left(D=0 \cdot 10 \mathrm{~h}^{-1}\right)$ with maltose as the carbon source

The presence of small amounts of ethanol in cultures growing at low oxygen feed results from the presence of this compound in the reservoir medium.

\begin{tabular}{|c|c|c|c|c|c|c|}
\hline \multicolumn{2}{|c|}{$\begin{array}{c}\text { Oxygen } \\
\left(\mathrm{mmol} \mathrm{h}^{-1} \mathrm{l}^{-1}\right)\end{array}$} & \multicolumn{2}{|c|}{$\begin{array}{c}\text { Maltose } \\
\left(\mathrm{g} \mathrm{l}^{-1}\right)\end{array}$} & \multirow{2}{*}{$\begin{array}{c}\text { Dry } \\
\text { weight } \\
\left(\mathrm{g} \mathrm{l}^{-1}\right)\end{array}$} & \multirow[t]{2}{*}{$\begin{array}{c}\text { Ethanol } \\
(\mathrm{mM})\end{array}$} & \multirow[t]{2}{*}{$\begin{array}{c}\text { Pyruvate } \\
\text { (mM) }\end{array}$} \\
\hline In & Out & In & Out & & & \\
\hline 2.5 & $2 \cdot 0$ & $4 \cdot 6$ & ND* & $0 \cdot 28$ & $10 \cdot 3$ & $<0.1$ \\
\hline $4 \cdot 7$ & $4 \cdot 0$ & $45 \cdot 5$ & $48 \cdot 4$ & 0.43 & $10 \cdot 2$ & $<0.1$ \\
\hline 4.7 & $3 \cdot 8$ & $4 \cdot 6$ & $4 \cdot 6$ & 0.38 & $4 \cdot 7$ & $<0.1$ \\
\hline 10.9 & $7 \cdot 0$ & $12 \cdot 3$ & $11 \cdot 0$ & $1 \cdot 88$ & $<1$ & $<0.1$ \\
\hline 14.5 & $11 \cdot 1$ & $10 \cdot 5$ & $9 \cdot 2$ & $1 \cdot 88$ & $<1$ & $<0.1$ \\
\hline 14.8 & $11 \cdot 2$ & $4 \cdot 6$ & $2 \cdot 6$ & $1 \cdot 76$ & $<1$ & $<0.1$ \\
\hline $15 \cdot 6$ & $11 \cdot 3$ & $4 \cdot 6$ & ND & 1.97 & $<1$ & $<0.1$ \\
\hline 18.0 & $12 \cdot 7$ & 6.8 & $1 \cdot 8$ & $3 \cdot 46$ & $<1$ & $<0.1$ \\
\hline $18 \cdot 1$ & $12 \cdot 8$ & $4 \cdot 6$ & ND & 3.07 & $<1$ & $<0.1$ \\
\hline $21 \cdot 1$ & $17 \cdot 2$ & 6.8 & $0 \cdot 8$ & $3 \cdot 21$ & $<1$ & $<0.1$ \\
\hline $22 \cdot 8$ & $19 \cdot 2$ & 5.5 & $4 \cdot 0$ & $2 \cdot 45$ & $<1$ & $<0.1$ \\
\hline 32.5 & $26 \cdot 2$ & $4 \cdot 6$ & 0.7 & $2 \cdot 87$ & $<1$ & $<0.1$ \\
\hline 47.6 & $40 \cdot 4$ & $4 \cdot 6$ & ND & $2 \cdot 90$ & $<1$ & $<0 \cdot 1$ \\
\hline
\end{tabular}

ND, Not determined.

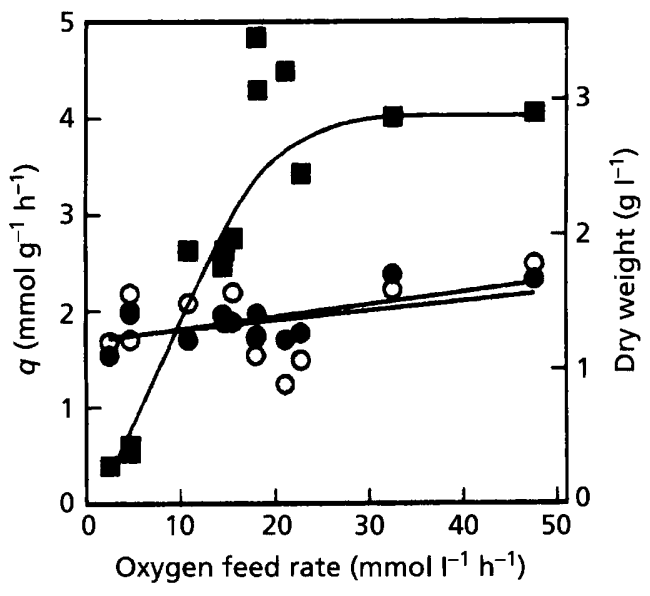

Fig. 6. Relation between oxygen feed rate and the dry weight (G), specific production rate of $\mathrm{CO}_{2}\left(q_{\mathrm{CO}_{2}}, \mathrm{O}\right)$ and specific consumption rate of oxygen $\left(q_{O_{2}},-\right.$ ) of $C$. utilis CBS 612, grown at different oxygen feed rates in chemostat cultures $\left(D=0.10 \mathrm{~h}^{-1}\right)$, with maltose as a carbon and energy source. Note that on the $x$-axis the oxygen feed rate is plotted and not, as in the other graphs, $q_{\mathrm{O}_{2}}$.

\section{Effects of oxygen feed on growth of $C$. utilis on maltose}

The effect of the oxygen feed rate on growth of C. utilis on maltose was markedly different from the three situations described above (Fig. 6). In all cultures, the ethanol concentration was lower than in the reservoir medium (Table 4). Apparently, alcoholic fermentation did not occur at any of the oxygen feed rates tested. Instead, maltose metabolism was respiratory over the whole range 


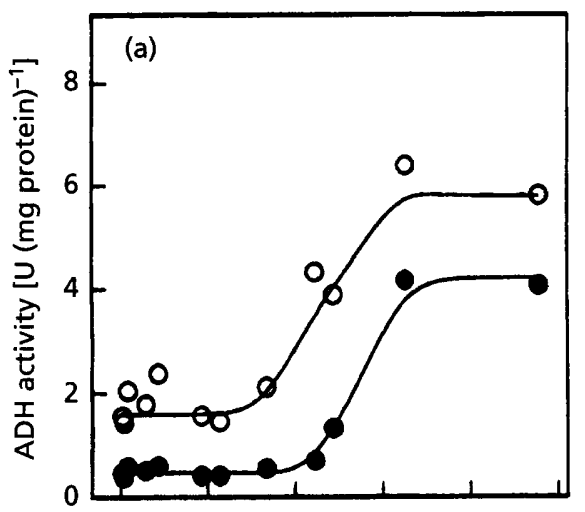

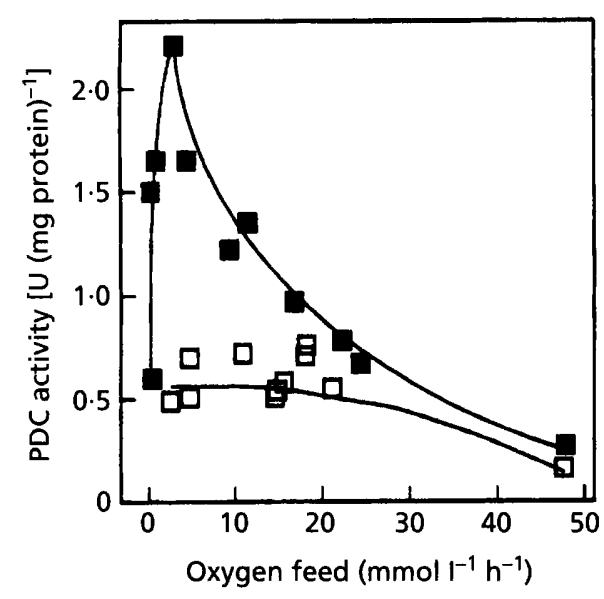

Fig. 7

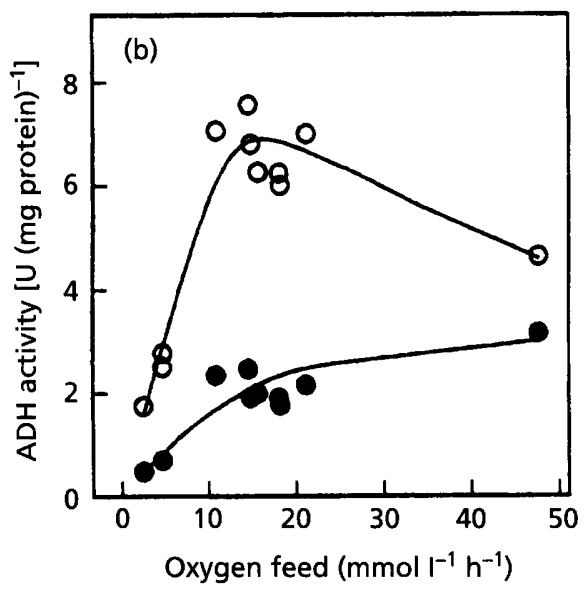

Fig. 8

Fig. 7. Relation between oxygen feed rate and PDC activity of C. utilis CBS 612, grown in chemostat cultures $\left(D=0 \cdot 10 \mathrm{~h}^{-1}\right)$ with glucose $(\square)$ or maltose $(\square)$ as a carbon and energy source.

Fig. 8. Relation between oxygen feed rate and ethanol-(O) and pentanol-(O) dependent ADH activities of $C$. utilis CBS 612 , grown in chemostat cultures $\left(D=0 \cdot 10 \mathrm{~h}^{-1}\right)$ with glucose (a) or maltose (b) as a carbon and energy source.

of oxygen feed rates tested, as indicated by the constant $q_{\mathrm{CO}_{2}}$ and $q_{\mathrm{O}_{2}}$ (Fig. 6). Since the $q_{\mathrm{O}_{2}}$ hardly changed, culture parameters were plotted against the oxygen feed rate. In contrast to the results on glucose, organic acids could not be detected in any of the cultures (only shown for pyruvate, Table 4).

At oxygen feed rates below $30 \mathrm{mmol} \mathrm{l}^{-1} \mathrm{~h}^{-1}$, residual maltose concentrations in the cultures increased and the amount of biomass decreased (Table 4, Fig. 6). At these suboptimal oxygen feed rates, the culture dry weight could not be increased by adding maltose to the reservoir media (Table 4). A dual limitation of sugar and oxygen, as observed during growth of $C$. utilis on glucose, could not be attained with maltose, and growth was only limited by oxygen. The high residual maltose concentrations resulted in small differences between culture and reservoir sugar concentrations. As a consequence, a large variation occurred in the calculated biomass yields and maltose fluxes (results not shown).

Due to the low culture dry weights at low oxygen feed rates, it was not possible to test at which oxygen feed rate maltose-grown cultures of $C$. utilis washed-out. The ethanol added to the medium reservoir accumulated in the culture at oxygen feed rates below $10.9 \mathrm{mmol} \mathrm{l}^{-1} \mathrm{~h}^{-1}$. With a biomass yield of $C$. utilis on ethanol of $0.69 \mathrm{~g} \mathrm{~g}^{-1}$ (Verduyn et al., 1991), ethanol present in the media $(12 \mathrm{mM})$ could only account for $0.38 \mathrm{~g}$ biomass $\mathrm{l}^{-1}$. The observed biomass concentrations and ethanol concentrations in the culture (Table 4) hence indicate that respiratory growth of $C$. utilis on maltose occurred at all oxygen feed rates.

C. utilis exhibited a clear Kluyver effect for maltose: alcoholic fermentation of the disaccharide was not observed, while both respiratory metabolism of maltose and fermentation of its hydrolysis product glucose were possible (Kluyver \& Custers, 1940; Sims \& Barnett, 1978). An explanation for this apparent intrinsic inability to ferment maltose might be the absence of the fermentative key enzymes pyruvate decarboxylase and/or alcohol dehydrogenase during growth on the disaccharide. Therefore, the activities of these enzymes were assayed in cell-free extracts of maltose-grown $C$. utilis. 


\section{Effect of oxygen on pyruvate decarboxylase and alcohol dehydrogenase activities of $\mathrm{C}$. utilis}

Pyruvate decarboxylase (PDC) activities in glucosegrown C. utilis increased from 0.3 to $2.2 \mathrm{U}$ (mg protein $)^{-1}$ with decreasing oxygen feed rates, parallel to the $q_{\text {ethanol }}$. An increase of PDC activities was also observed in the maltose-grown cultures: with decreasing oxygen feed, PDC activities increased from 0.2 to $0.6 \mathrm{U}$ (mg protein) ${ }^{-1}$ (Fig. 7). The maximum fermentation rates that can be sustained by the PDC activities measured in cell-free extracts can be calculated by assuming a soluble protein content of yeast biomass of $30 \%$. Thus, the maximum observed PDC activity of $0.6 \mathrm{U}$ (mg protein) ${ }^{-1}$ would be sufficient to account for a maximum rate of ethanol formation of as high as $11 \mathrm{mmol}(\mathrm{gdry} \mathrm{wt})^{-1} \mathrm{~h}^{-1}$.

Various forms of the second key enzyme in alcoholic fermentation, alcohol dehydrogenase (ADH), occur in yeasts (Verduyn et al., 1988). S. cerevisiae, for example, contains three isoenzymes: a constitutive cytoplasmic $\mathrm{ADH}$ functioning in alcoholic fermentation, an inducible cytoplasmic ADH active during growth on ethanol, and a mitochondrial ADH of which the function is unknown. The 'fermentative' ADH activity can be differentiated from the other two ADH activities by its inability to use pentanol as a substrate (Lutstorf \& Megnet, 1968). A similar situation probably exists in $C$. utilis, although the role of the several isoenzymes has been less well studied. During growth of $C$. utilis on glucose, the pentanoldependent ADH activity was approximately $4 \mathrm{U}(\mathrm{mg}$ protein $)^{-1}$ at high oxygen feed rates and decreased sharply to a basal level of $0 \cdot 2 \mathrm{U}$ (mg protein $)^{-1}$ when the oxygen feed rate was reduced. The high pentanol-dependent ADH activities coincided with the consumption of ethanol present in the reservoir media. Ethanol-dependent ADH activity showed a similar pattern, but was approximately $2 \mathrm{U}$ (mg protein $)^{-1}$ higher in all cultures, suggesting a constitutive expression of the 'fermentative' ADH. During growth on maltose, pentanol-dependent ADH activity remained high over a broader oxygen feed range than during growth on glucose. Also in this case a good correlation existed with the occurrence of ethanol cometabolism. Under oxygen-limited conditions, the ADH activities of maltose-grown cells were equal to or higher than those of glucose-grown cells (Fig. 8).

\section{Production of glycerol}

In equations 1 to 4 , fermentative sugar metabolism in yeasts has been simplified by assuming that ethanol is the sole fermentation product. However, it is well-known that in additional to ethanol, other metabolites may be excreted by yeasts. Quantitatively, glycerol is one of the major byproducts of alcoholic fermentation under anaerobic conditions.

Glycerol formation by yeasts may have various functions, some involved in osmoregulation. Under anaerobic conditions, however, the main physiological role of glycerol formation is related to redox metabolism. Since, as mentioned above, yeast biomass is more oxidized than

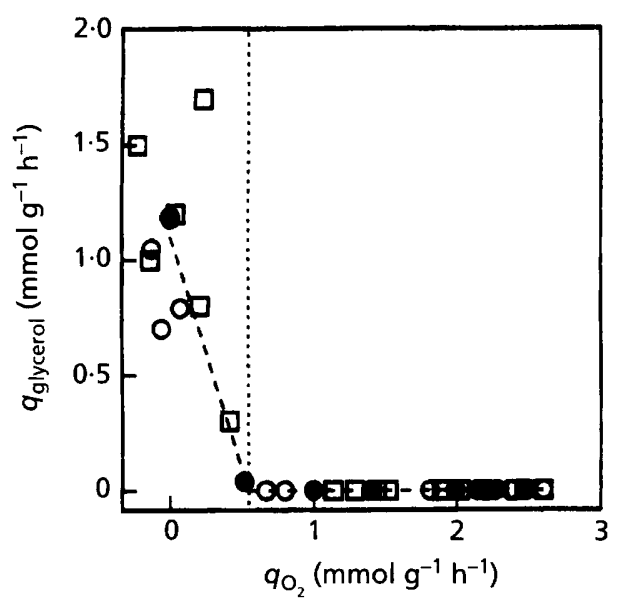

Fig. 9. Relation between specific oxygen uptake rate $\left(q_{\mathrm{O}_{2}}\right)$ and specific glycerol production rate $\left(q_{\text {glycerol }}\right)$ of $S$. cerevisiae CBS 8066 (circles) and C. utilis CBS 612 (squares), grown at different oxygen feed rates in chemostat cultures $\left(D=0.10 \mathrm{~h}^{-1}\right)$ with glucose (open symbols) or maltose (filled symbols) as a carbon and energy source. The dashed line indicates the $q_{\mathrm{O}_{2}}$ value below which glycerol formation must occur to obtain a closed redox balance.

the carbohydrate substrate, NADH is produced during assimilation of sugars. In the presence of oxygen, reduced cofactors can be reoxidized by respiration. When respiration is not possible, yeasts can reduce dihydroxyacetone phosphate to glycerol to close the redox balance (Holzer et al., 1963; Gancedo et al., 1968; Oura, 1977).

Glycerol formation branches off from the glycolytic pathway before the reactions that involve substrate-level phosphorylation. Therefore, formation of $1 \mathrm{~mol}$ glycerol from glucose requires the net hydrolysis of $1 \mathrm{~mol}$ ATP. In contrast, respiratory reoxidation of reduced cofactors yields metabolic energy by oxidative phosphorylation. To investigate the regulation of redox metabolism in yeasts, we studied the formation of glycerol at limiting oxygen feed rates.

Verduyn et al. (1990) reported that formation of $1 \mathrm{~g}$ $S$. cerevisiae biomass results in the formation of $11 \mathrm{mmol}$ $\mathrm{NADH}$. Under respiratory conditions, this NADH can be oxidized with $5.5 \mathrm{mmol}$ oxygen. If redox metabolism in yeasts is regulated to minimize ATP expenditure for glycerol formation, glycerol should not be produced at specific oxygen consumption rates above $5.5 \times 0 \cdot 1=$ $0.55 \mathrm{mmol} \mathrm{g}^{-1} \mathrm{~h}^{-1}$ (product of oxygen requirement per unit yeast biomass and dilution rate). This could indeed be confirmed experimentally for growth of $S$. cerevisiae on either maltose or glucose, and for $C$. utilis grown on glucose (Fig. 9). Cultures in which $q_{\mathrm{O}_{2}}$ was decreased below this threshold invariably produced glycerol (Fig. 9). The glycerol production rates in anaerobic cultures of $S$. cerevisiae were in good agreement with the data of Verduyn et al. (1990). No glycerol formation was observed in the cultures of $C$. utilis grown on maltose (data not shown), consistent with their respiratory mode of metabolism. 
The physiological necessity of glycerol production at very low oxrgen feeds implies that the energetic efficiencr of sugar metabolism is dependent on the oxygen feed. When the reducing equivalents produced during anabolic processes are oxidized by respiration, ATP is produced. However, when reoxidation occurs via glycerol formation, ATP is consumed. Consequently, equations 1 to 4 that were used to model growth and alcoholic fermenration in oxygen-limited cultures are an oversimplification.

\section{DISCUSSION}

\section{Regulation of alcoholic fermentation in yeasts}

Crabree-positive yeasts, including $f$. cerenisiat, have a very strong tendency towards alcoholic fermentation. In practicc, ethanol formation by these yeasts can only be avoided by growth under fully aerobic conditions with a limited supply of sugar. In conerast, fermentative metabolism in (Crabtree-negative yeasts, including $C$. utilis, cannot be induced in the presence of excess oxrgen. However, under oxygen-limited growth conditions, fermentation rates in Crabtree-positive and Crabtrec-negative yeasts are comparable.

In the Crabtree-posirive reast S. cererisiat, high levels of the fermentative key enzyme PDC are present under acrotsic, glucose-limited growth conditions. 'Ihese activties increase only approximately twofold upon a switch to respiro-fermentative growth. In contrast, only low PI) a activities could be detceted in aerobic, glucosclimited cultures of the Crabtree-negative yeast C. wilis. These activities increased sharply when $C$. wilis was grown under oxygen limitation, suggesting that oxygen may be a key factor in the regulation of PDC activity in this yease (Franzblau \& Sinclair, 1983). In fact, in cultures in which growth is limited only by glucose (i.c. at dissolved-oxygen concentrations above ca. $1 \%$ air saturation) the actual dissolved-oxygen concentration had a significant effect on PDC activitics (data not shown). These data suggest that regulation of sugar metabolism at the level of pyruvate may well be responsible for the different behaviour of Crabtree-positive and Crabtreenegative yeasts.

\section{Oxygen requirements for growth}

()xygen plays a dual role in yeast physiology: it is used as the terminal elcctron acceptor for mitochondrial respiration and for assimilatory oxygenation reactions. Respiration has two major functions: oxidation of reduced cotactors and generation of metabolic encrgy in the form of ATP. Linder oxygen-limited conditions, energ! transduction can be taken over by alcoholic fermentation. However, the conversion of glucose into ethanol is redoxneutral, and can therefore not be used to reoxidize the "excess" reducing equivalents generared in assimilation. Glycerol production can serve as an alternative redox sink but requires a net input of ATP (van Dijken \& Scheffers, 1986). Theorerically, therefore, yeasts can optimize their sugar metabolism under oxygen-limited growth con- ditions by preferentially using oxygen for the regeneration of 'excess' $\mathrm{N} \wedge \mathrm{DH}$. The data presented in Fig. 9 indicate that in both S. cerevisiae and C. utilis, sugar metabolism is regulated in this way. At present, it is unclear at which level the preferential use of oxrgen as an clectron acceptor for NADH regeneration is regulated. At the kinetic level, a higher affinity of the mitochondrial external NiDH dehydrogenase complex for $\mathrm{N} / \mathrm{Nl} H$ as compared to the cytosolic dihydroxyacetone phosphate reductase could be significant.

In addition to its role in respiration, oxygen has an essential role in assimilatory oxygenation reactions. Cellu lar constituents, the synthesis of which require molecular oxygen, must be added to growith media to allow anaerobic growth. In the case of $S$. ceretisiae, these 'anaerobic growth facrors' are well-defined, and the organism grows well anaerobically in defined media supplemented with ergosterol, unsaturated fatty acids and nicotinic acid (Andreasen \& Stier, 1953, 1954) (Table 1. Figs 2 and 3 ). In the same medium, however, $C$. utilis was not able to grow at a tate of $0.10 \mathrm{~h}^{1}$ at $\%$ ro oxygen feed (Table 4, Fig. 6). This confirmed earlier reports that C. utilis is unable to grow anacrobically at rates above $0.01 \mathrm{~h}^{-1}$ (Visser $\ell t$ al., 1990). C. . wtilis is not an exception in this respect: apart from S. cererisiae, none of the type species of the 75 yeast gencra studied were able to grow under strictly anaerebic conditions with specific growth rates higher than $0 \cdot 10 \mathrm{~h}^{-1}$ (Visser $t$ t al, 1990$)$. It is as yet unclear if unidentitied assimilatory oxygen requirements ate involved, or that these yeasts require oxygen for other cellular processes. This hitherto unexplained inability of non-5. cererisiae yeasts to grow anaerobically is of great importance for some industrial applications of these organisms. The range of sugar substrates is much larger for these yeasts than for $S$. cererisiut. Numerous processes have been suggested in which non-Saccharomyces yeasts could be used for the production of ethanol from waste streams and complex raw materials. A fact, overlooked in many of these publications, is that oxygen is required by these yeasts, even during fermentative growth. At very low oxygen feeds, growth (and eventually fermentation) becomes inhibited due to the intrinsic inability of these yeasts to grow anaerobically. At higher oxygen feeds, the glycolytic flux is preferentially directed towards respiration, thereby lowering the ethanol yield. This makes it rather difficult to optimize ethanot yields in large-scale industrial fermentations using non-Sactharomyces yeasts. Howerer, in small-scale laboratory experiments, the oxygen requirements of these yeasts may easily go unnoticed. For example, if in the present study, oxigenpermeable silicone tubing (instead of Norprene) was used on the fermenters, $C$. willis could be grown at a dilution rate of $0.10 \mathrm{~h}^{-1}$ in cultures sparged with pure nitrogen gas.

\section{The Kluyver effect}

The observation of Sims \& Barnet (1978) that C.. willi: exhibits a Kluver effect during growth on maltose is clearly supported by the results presented in this study. 
Over a range of oxygen feed rates, $C$. utilis grew strictly respiratorily on maltose, without the occurrence of alcoholic fermentation (Fig. 6, Table 4). Our results imply that, even in a situation where the enzymes for maltose uptake and hydrolysis were present, $C$. utilis did not ferment this disaccharide. In contrast, during oxygenlimited growth of $C$. utilis on glucose, respiration and fermentation occurred simultaneously (Fig. 5). The fermentation rates in these cultures (Fig. 5) were equal to or even exceeded those of the Kluyver-negative yeast $S$. cerevisiae, which exhibited a respiro-fermentative metabolism during oxygen-limited growth on both glucose and maltose (Fig. 3).

The intrinsic inability of $C$. utilis to ferment maltose is important for the interpretation of the results of Sims \& Barnett (1978). From experiments with a $\mathrm{CO}_{2}$ electrode, these authors concluded that the fermentative activity of this yeast with maltose responded rapidly and reversibly to changes in the oxygen concentration. The results presented in this paper indicate that the $\mathrm{CO}_{2}$ production measured in the experiments of Sims \& Barnett (1978) was due to respiratory rather than fermentative maltose metabolism.

In earlier reports, low PDC activities have been reported for Kluyver-positive yeasts grown on disaccharides (Sims \& Barnett, 1991 ; Sims et al., 1991). In the present study, the PDC and ADH activities in C. utilis grown on maltose in oxygen-limited chemostat cultures (Figs 7 and 8) were theoretically sufficient to sustain a $q_{\text {ethanol }}$ of $11 \mathrm{mmol}$ $\mathrm{g}^{-1} \mathrm{~h}^{-1}$. This theoretical flux is even higher than that observed in $S$. cerevisiae grown under the same conditions. Apparently, in C. utilis the Kluyver effect for maltose is not caused by an insufficient capacity of PDC and ADH. Also, the absence of significant concentrations of organic acids in the maltose-grown $C$. utilis cultures (Table 4) indicates that a limited capacity of these fermentative enzymes is unlikely to cause the Kluyver effect. Instead, maltose metabolism appears to be regulated before the level of pyruvate, i.e. at the level of disaccharide uptake, hydrolysis or glycolysis.

An inhibition of disaccharide transport activity by the absence of oxygen has been proposed as one of the possible causes of the Kluyver effect (Sims \& Barnett, 1978; Schulz \& Höfer, 1986). However, low, but significant disaccharide uptake rates have been reported for Kluyver-positive yeasts under anaerobic conditions (Sims \& Barnett, 1978; Schulz \& Höfer, 1986). Barnett \& Sims (1982) therefore concluded that the Kluyver effect cannot be solely caused by absence of transport activity. This conclusion is supported by the present study: under all oxygen feed regimes studied, $C$. utilis continued to take up and respire maltose. The total absence of alcoholic fermentation in maltose-grown, oxygen-limited cultures of $C$. utilis indicates that uptake and hydrolysis of maltose were stoichiometrically balanced with the amount of this disaccharide that could be respired. A mechanism which tunes disaccharide uptake and hydrolysis in response to oxygen concentration or redox potential may indeed be responsible for this phenomenon.
The original description of the Kluyver effect (Sims \& Barnett, 1978) discriminated between aerobic and anaerobic utilization of sugars. However, C. utilis and other yeasts exhibiting the Kluyver effect are not capable of anaerobic growth (Visser et al., 1990). Furthermore, the data presented here indicate that occurrence of the Kluyver effect does not depend on the oxygen concentration, but reflects an intrinsic inability to perform fermentative metabolism with the disaccharide. We therefore propose a new definition of the Kluyver effect: 'The inability to ferment certain disaccharides to ethanol and $\mathrm{CO}_{2}$, even though respiratory metabolism of the disaccharides and alcoholic fermentation of the component hexose(s) can occur'.

\section{ACKNOWLEDGEMENTS}

We are indebted to Dr Cornel Verduyn (BIRD Engineering, Schiedam, The Netherlands) for valuable discussions and Kjeld Bangma and Yvonne van Klei for their skilful technical assistance.

\section{REFERENCES}

Andreasen, A. A. \& Stier, T. J. B. (1953). Anaerobic nutrition of Saccharomyces cerevisiae. I. Ergosterol requirement for growth in a defined medium. J Cell Comp Pbysiol 41, 23-26.

Andreasen, A. A. \& Stier, T. J. B. (1954). Anaerobic nutrition of Saccharomyces cerevisiae. II. Unsaturated fatty acid requirement for growth in a defined medium. J Cell Comp Physiol 43, 271-281.

Barnett, J. A. (1992). Some controls on oligosaccharide utilization by yeasts: the physiological basis of the Kluyver effect. FEMS Microbiol Lett 100, 371-378.

Barnett, J. A., Payne, R. W. \& Yarrow, D. (1990). Yeast : characteristics and identification, 2nd edn. Cambridge: Cambridge University Press.

Barnett, J. A. \& Sims, A. P. (1982). The requirement of oxygen for the active transport of sugars into yeasts. $J$ Gen Microbiol 128, 2303-2312.

Brown, C. M. \& Rose, A. H. (1969). Fatty-acid composition of Candida utilis as affected by growth temperature and dissolvedoxygen tension. J Bacteriol 99, 371-378.

Bruinenberg, P. M., de Bot, P. H. M., van Dijken, J. P. \& Scheffers, W. A. (1984). NADH-linked aldose reductase: the key to anaerobic alcoholic fermentation of xylose by yeasts. Appl Microbiol Biotechnol 19, 256-260.

Busturia, A. \& Lagunas, R. (1986). Catabolite inactivation of the glucose transport system in Saccharomyces cerevisiae. J Gen Microbiol 132, 379-385.

Carrascosa, J. M., Viguera, M. D., Núnez de Castro, I. \& Scheffers, W. A. (1981). Metabolism of acetaldehyde and Custers effect in the yeast Brettanomyces abstinens. Antonie Leeuwenboek. 47, 209-215.

Clifton, D., Walsh, R. B. \& Fraenkel, D. G. (1993). Functional studies of yeast glucokinase. J Bacteriol 175, 3289-3294.

Custers, M. T. J. (1940). Onderzoekingen over bet gistgeslacht Brettanomyces. PhD Thesis, Delft University of Technology, The Netherlands.

Cysewski, G. R. \& Wilke, C. R. (1976). Utilization of cellulosic materials through enzymatic hydrolysis. I. Fermentation of hydrolysate to ethanol and single-cell protein. Biotechnol Bioeng 18, 1297-1313. 
van Dijken, J. P. \& Scheffers, W. A. (1986). Redox balances in the metabolism of sugars by yeasts. FEMS Microbiol Rev 32, 199-224.

van Dijken, J. P., van den Bosch, E., Hermans, J. J., Rodrigues de Miranda, L. \& Scheffers, W. A. (1986). Alcoholic fermentation by 'non-fermentative' yeasts. Yeast 2, 123-127.

Fiechter, A., Fuhrman, G. F. \& Kăppeli, O. (1981). Regulation of glucose metabolism in growing yeast cells. Adv Microb Pbysiol 22, 123-183.

Franzblau, S. G. \& Sinclair, N. A. (1983). Induction of pyruvate decarboxylase in Candida utilis. Mycopathologia 83, 29-33.

Furukawa, K., Heinzle, E. \& Dunn, I. J. (1983). Influence of oxygen on the growth of Saccharomyces cerevisiae in continuous culture. Biotechnol Bioeng 25, 2293-2317.

Gancedo, C., Gancedo, J. M. \& Sols, A. (1968). Glycerol metabolism in yeasts. Pathways of utilization and production. Eur J Biochem 5, 165-172.

Gaunt, D. M., Degn, H. \& Lloyd, D. (1988). The influence of oxygen and organic hydrogen acceptors on glycolytic carbon dioxide production in Brettanomyces anomalus. Yeast 4, 249-255.

Gommers, P. J. F., van Schie, B. J., van Dijken, J. P. \& Kuenen, J. G. (1988). Biochemical limits to microbial growth yields: an analysis of mixed substrate utilization. Biotechnol Bioeng 32, 86-94.

Grosz, R. \& Stephanopoulos, G. (1990). Physiological, biochemical, and mathematical studies of micro-aerobic continuous ethanol fermentation by Saccharomyces cerevisiae. I. Hysteresis, oscillations, and maximum specific ethanol productivities in chemostat culture. Biotechnol Bioeng 36, 1006-1019.

Höfer, M. \& Nassar, F. R. (1987). Aerobic and anaerobic uptake of sugars in Schizosaccharomyces pombe. J Gen Microbiol 133, 2163-2172.

Holzer, H., Bernardt, W. \& Schneider, S. (1963). Zur Glycerin bildung in Bäckerhefe. Biocbem Z 336, 495-509.

Kăppeli, O. (1986). Regulation of carbon metabolism in Saccharomyces cerevisiae and related yeasts. Adv Microb Physiol 28, 181-209.

Käppeli, O. \& Sonnleitner, B. (1986). Regulation of sugar metabolism in Saccharomyces-type yeast: experimental and conceptual considerations. Crit Rev Biotechnol 4, 299-325.

Käppeli, O., Gschwend-Petrik, M. \& Fiechter, A. (1985a). Transient responses of Saccharomyces uvarum to a change of the growthlimiting nutrient in continuous culture. J Gen Microbio/ 131, 47-52.

Käppeli, O., Arreguin, M. \& Rieger, M. (1985b). The respirative breakdown of glucose by Saccharomyces cerevisiae: an assessment of a physiological state. J Gen Microbiol 131, 1411-1416.

Kluyver, A. J. \& Custers, M. T. J. (1940). The suitability of disaccharides as respiration and assimilation substrates for yeasts which do not ferment these sugars. Antonie Leeuwenboek 6, 121-162.

Kuriyama, H. \& Kobayashi, H. (1993). Effects of oxygen supply on yeast growth and metabolism in continuous fermentation. J Ferment Bioeng 75, 364-367.

Lagunas, R. (1986). Misconceptions about the energy metabolism of Saccharomyces cerevisiae. Yeast 2, 221-228.

Lagunas, R., Dominguez, C., Busturia, A. \& Sáez, M. J. (1982). Mechanisms of appearance of the Pasteur effect in Saccharomyces cerevisiae: inactivation of sugar transport systems. J Bacteriol 152, $19-25$.

Laplace, J. M., Delgenes, J. P., Moletta, R. \& Navarro, J. M. (1991). Alcoholic fermentation of glucose and xylose by Pichia stipitis, Candida shehatae, Saccharomyces cerevisiae and Zymomonas mobilis: oxygen requirement as a key factor. Appl Microbiol Biotechnol 36, 158-162.
Lloyd, D. \& James, C. J. (1987). The Pasteur effect in yeasts: mass spectrometric monitoring of oxygen uptake, and carbon dioxide and ethanol production. FEMS Microbiol Lett 42, 27-31.

Lutstorf, U. \& Megnet, R. (1968). Multiple forms of alcohol dehydrogenase in Saccharomyces cerevisiae. I. Physiological control of $\mathrm{ADH}-2$ and properties of ADH-2 and ADH-4. Arch Biochem Biopbys 126, 933--944.

Moss, F. J., Rickard, P. A. D., Beech, G. A. \& Bush, F. E. (1969). The response by microorganisms to steady state growth in controlled concentrations of oxygen and glucose. I. Candida utilis. Biotechnol Bioeng 11, 561-580.

Nishizawa, Y., Dunn, I. J. \& Bourne, J. R. (1980). The influence of oxygen and glucose on anaerobic ethanol production. In Proceedings of the 7th Symposium on Continuous Cultivation of Microorganisms, pp. 605-612. Edited by B. Sikyta, Z. Fencl \& V. Poláček. Prague: Institute of Microbiology, Csechoslovak Academy of Sciences.

Oura, E. (1977). Reaction products of yeast fermentations. Process Biochem 12, 19-35.

Petrik, M., Käppeli, O. \& Fiechter, A. (1983). An expanded concept for the glucose effect in the yeast Sacharomyces uvarum: involvement of short- and long-term regulation. J Gen Microbiol 129, 43-49.

Postma, E., Scheffers, W. A. \& van Dijken, J. P. (1988). Adaptation of the kinetics of glucose transport to environmental conditions in the yeast Candida utilis CBS 621: a continuous-culture study. J Gen Microbiol 134, 1109-1116.

Postma, E., Scheffers, W. A. \& van Dijken, J. P. (1989a). Kinetics of growth and glucose transport in glucose-limited chemostat cultures of Saccharomyces cerevisiae CBS 8066. Yeast 5, 159-165.

Postma, E., Verduyn, C., Scheffers, W. A. \& van Dijken, J. P. (1989b). Enzymic analysis of the Crabtree effect in glucose-limited chemostat cultures of Saccharomyces cerevisiae. Appl Environ Microbiol 55, 468-477.

Scheffers, W. A. (1966). Stimulation of fermentation in yeasts by acetoin and oxygen. Nature 210, 533-534.

Schulz, B. \& Höfer, M. (1986). Utilization of lactose in nonrespiring cells of the yeast Debaryomyces polymorphus. Arch Microbiol 145, 367-371.

Sims, A. P. \& Barnett, J. A. (1978). The requirement of oxygen for the utilization of maltose, cellobiose and D-galactose by certain anaerobically fermenting yeasts (Kluyver effect). $J$ Gen Microbiol 106, 277-288.

Sims, A. P. \& Barnett, J. A. (1991). Levels of activity of enzymes involved in anaerobic utilization of sugars by six yeast species: observations towards understanding the Kluyver effect. FEMS Microbiol Lett 77, 295-298.

Sims, A. P., Kopetzki, E., Schulz, B. \& Barnett, J. A. (1984). The use of phenolic glycosides for studying the aerobic or anaerobic transport of disaccharides into yeasts. J Gen Microbiol 130, 1933-1940.

Sims, A. P., Stălbrand, H. \& Barnett, J. A. (1991). The role of pyruvate decarboxylase in the Kluyver effect in the food yeast, Candida utilis. Yeast 7, 479-487.

van Urk, H., Mak, P. R., Scheffers, W. A. \& van Dijken, J. P. (1988). Metabolic responses of Saccharomyces cerevisiae CBS 8066 and Candida utilis CBS 621 upon transition from glucose limitation to glucose excess. Yeast 4, 283-291.

van Urk, H., Schipper, D., Breedveld, G. J., Mak, P. R., Scheffers, W. A. \& van Dijken, J. P. (1989). Localization and kinetics of pyruvate-metabolizing enzymes in relation to aerobic alcoholic fermentation in Saccharomyces cerevisiae CBS 8066 and Candida utilis CBS 621. Biocbim Biopbys Acta 992, 78-86.

Verduyn, C., Breedveld, G. J., Scheffers, W. A. \& van Dijken, J. P. 
(1988). Substrate specificity of alcohol dehydrogenase from the yeasts Hansenula polymorpha CBS 4732 and Candida utilis CBS 621. Yeast 4, 143-148.

Verduyn, C., Postma, E., Scheffers, W. A. \& van Dijken, J. P. (1990). Physiology of Saccharomyces cerevisiae in anaerobic glucoselimited chemostat cultures. J Gen Microbiol 136, 395-403.

Verduyn, C., Stouthamer, A. H., Scheffers, W. A. \& van Dijken, J.P. (1991). A theoretical evaluation of growth yields of yeasts. Antonie Leeuwenhoek 59, 49-63.

Visser, W., Scheffers, W. A., Batenburg-van der Vegte, W. H. \& van Dijken, J.P. (1990). Oxygen requirements of yeasts. Appl Environ Microbiol 56, 3785-3792.
Weusthuis, R. A., Adams, H., Scheffers, W. A. \& van Dijken, J. P. (1993). Energetics and kinetics of maltose transport in Saccharomyces cerevisiae: a continuous-culture study. Appl Environ Microbiol 59, 3102-3109.

Wijsman, M. R., van Dijken, J. P., van Kleeff, B. H. A. \& Scheffers, W. A. (1984). Inhibition of fermentation and growth in batch cultures of the yeast Brettanomyces intermedius upon a shift from aerobic to anaerobic conditions (Custers effect). Antonie Leewwenhoek 50, 183-192.

Received 8 October 1993; revised 29 November 1993; accepted 7 December 1993) 